\title{
'Baumol's Diseases': The Case of Switzerland
}

\author{
Jochen HarTwig ${ }^{a}$
}

JEL-Classification: C12, C23, O41, O47, O52

Keywords: Baumol's disease, productivity growth, Switzerland

\section{Introduction}

William J. Baumol's article "Macroeconomics of Unbalanced Growth" (BAUmoL, 1967 ) is widely regarded as a major contribution to the literature on structural change. The model presented in that article predicts that the process of deindustrialization will have some unpleasant consequences from an economic policy perspective. Most notably, the model foresees that large service industries financed mainly through taxes and social contributions - like health care and education for instance - will acquire ever-larger shares of total expenditures. Acknowledging Baumol's analysis, a perceived 'cost explosion' in the non-business sector of the economy is sometimes referred to as 'Baumol's disease'.

William D. Nordhaus suggests speaking of 'Baumol's diseases' instead (see Nordhaus, 2008) because the 'cost explosion' is not the only misfortune Baumol's model anticipates. According to the model, the ultimate reason why costs 'explode' in health care and education is that productivity growth in these industries is low. It follows that if such industries receive an ever-higher weight in the economy, the aggregate productivity growth rate will decline over time. Nordhaus calls this prediction of the model the 'growth disease'.

Against the backdrop of earlier empirical analyses, which mostly relied on the use of descriptive statistics, Nordhaus (2008) has introduced an elegant panel-econometric testing framework for Baumol's model. In the present paper I intend to apply Nordhaus's testing methodology to Swiss data in order to find out whether Switzerland - like the U.S. according to Nordhaus's findings - suffers from 'Baumol's diseases'.

KOF Swiss Economic Institute at ETH Zurich, Weinbergstrasse 35, 8092 Zurich. Email: hartwig@kof.ethz.ch. I would like to thank Yngve Abrahamsen, Bernd Schips, an anonymous referee, and the editor for their thoughtful comments on earlier versions of this paper. The usual disclaimer applies. 
The paper is organised as follows. The next section will briefly restate Baumol's model formally. This is something that Nordhaus abstains from, but it will be helpful to deduce the testable implications and predictions of the model. Section 3 will explain the testing framework, and section 4 will discuss the data. The results for the tests of whether Switzerland suffers from 'Baumol's diseases' are presented in section 5 and compared with the benchmarks set by Nordhaus. Some notable differences between the Swiss and the U.S. results will surface. The last section offers some tentative explanations of why the Swiss results depart from those for the U.S.

\section{Baumol's Model of Unbalanced Growth}

Baumol presents a model in which the economy is divided into a 'progressive' and a 'nonprogressive' - or 'stagnant' - sector. He assumes that labour productivity grows only in the progressive sector, while wages grow in both sectors at a rate set by the productivity growth in the progressive sector. Formally, this can be stated as:

$$
\begin{gathered}
Y_{1 t}=a L_{1 t}, \\
Y_{2 t}=b L_{2 t} e^{r t}, \\
W_{t}=W e^{r t},
\end{gathered}
$$

with $Y_{1}$ and $Y_{2}$ as output in the two sectors at time $t, L_{1}$ and $L_{2}$ as quantities of labour employed in the two sectors, $r$ as the (constant) growth rate of labour productivity in the progressive sector (2), $W$ as the wage rate, and $a$ and $b$ as constants.

This simple model has a couple of interesting implications which Baumol draws out. From (1) to (3), we obtain

$$
\begin{gathered}
C_{1}=\frac{W_{t} L_{1 t}}{Y_{1 t}}=\frac{W e^{r t} L_{1 t}}{a L_{1 t}}=\frac{W e^{r t}}{a}, \\
C_{2}=\frac{W_{t} L_{2 t}}{Y_{2 t}}=\frac{W e^{r t} L_{2 t}}{b L_{2 t} e^{r t}}=\frac{W}{b} .
\end{gathered}
$$

That is, costs per unit of output in the stagnant sector tend toward infinity while they stay constant in the progressive sector. Since relative costs also tend toward 
infinity $\left(C_{1} / C_{2}=b e^{r t} / a\right)$, the stagnant sector will vanish under 'normal' circumstances - that is, when prices rise in proportion to costs and when demand is price-elastic. Yet, parts of the stagnant sector produce necessities for which the price elasticity is very low. Baumol calls attention to education and health care as prime examples. To account for this fact, he assumes that the relation of real output of the two sectors remains unchanged:

$$
\left(\frac{b}{a}\right) \frac{Y_{1}}{Y_{2}}=\frac{L_{1}}{L_{2} e^{r t}}=K
$$

where $K$ is a constant. With $L\left(=L_{1}+L_{2}\right)$ denoting the labour force, it follows:

$$
L_{1}=\left(L-L_{1}\right) K e^{r t} \Leftrightarrow L_{1}=\frac{L K e^{r t}}{1+K e^{r t}}
$$

and

$$
L_{2}=L-L_{1}=\frac{L}{1+K e^{r t}}
$$

implying that, over time $(t \rightarrow \infty), L_{1}$ tends toward $L$ and $L_{2}$ tends toward zero. The model thus predicts structural change in terms of a perpetual shift of both expenditures and employment toward the stagnant sector.

Finally, it can be shown what happens to the GDP growth rate under the assumption of constant 'real shares'. Let $I$ be an index for real GDP which is calculated as a weighted average of the value added of the two sectors:

$$
I=B_{1} Y_{1}+B_{2} Y_{2}=B_{1} a L_{1}+B_{2} b L_{2} e^{r t} .
$$

Then, if we insert (7) and (8) into (9) we get:

$$
I=\frac{L\left(K B_{1} a+B_{2} b\right) e^{r t}}{1+K e^{r t}}=\frac{R e^{r t}}{1+K e^{r t}},
$$

with

$$
R=L\left(K B_{1} a+B_{2} b\right)
$$

Applying the quotient rule leads to:

$$
\frac{d I}{d t}=\frac{R\left[r e^{r t}\left(1+K e^{r t}\right)-K r e^{2 r t}\right]}{\left(1+K e^{r t}\right)^{2}}=\frac{r R e^{r t}}{\left(1+K e^{r t}\right)^{2}} .
$$


We can calculate the growth rate of real GDP as:

$$
\frac{\left(\frac{d I}{d t}\right)}{I}=\frac{r}{1+K e^{r t}} .
$$

It follows that, over time $(t \rightarrow \infty)$, the GDP growth rate drops asymptotically to zero ceteris paribus. ${ }^{1}$

The model has six implications that can be tested empirically. Two of them are assumptions; the other four are consequences from the model's assumptions, some of which are undesirable from an economic policy perspective (that's why Nordhaus calls them 'diseases').

1. The cost and price disease. The model implies that average costs and prices in stagnant industries will grow relative to the progressive industries. To lend empirical support to the cost and price disease, we would need to find a statistically significant negative correlation between productivity growth and price growth across industries.

2. The 'constant real share' assumption. Baumol assumes that the relation of real output of the two sectors remains constant. This assumption has been rephrased as the 'real share maintenance' hypothesis (although, conceptually, the notion of 'real' output shares does not make much sense). Some scholars regard the constancy of the 'real share' of the services sector as a 'stylized fact' (Gundlach, 1994; ten RaA and SchettKat, 2001), others address it as the 'service paradox' (PUgno, 2006) because, given the rise in relative service prices, one would expect a declining demand and a drop in the 'real share' of services. Empirically, if the 'real shares' in fact remain constant, there should be no significant correlation between productivity growth and real output growth across industries.

3. Unbalanced nominal growth. As a consequence of bullet points (1) and (2), there should be a significantly negative correlation between productivity growth and nominal output (value added) growth across industries. In this case, the share of progressive industries' value added in nominal GDP would drop.

4. Declining employment shares of progressive industries. This is evident from eqs. (7) and (8) above. Across industries, the model predicts a significantly negative correlation between productivity growth and employment growth.

1 Ceteris paribus here especially means that $L$ remains constant. If $L$ grows at the rate $n$, then $n$ must be added at the right hand side of (13). Long-run stagnation then occurs for per-capita GDP. 
5. The assumption of uniform wage growth. Baumol assumes uniform wage growth across industries. If this assumption was valid, wage growth should not be correlated with productivity growth.

6. The growth disease. Baumol's model predicts that unbalanced productivity growth will lead to a decrease in the growth rate of overall GDP over time. This growth pessimism has always been more controversial than the proposition of the cost and price disease derived from Baumol's model. Oulton (2001), for instance, was able to show that if the tertiary sector produces intermediate services instead of services to the final consumer, the aggregate productivity (and hence the GDP) growth rate may rise over time rather than fall. SASAKI (2007), however, vindicated Baumol's result of a tendency for the economy to stagnate, showing that the GDP growth rate will decline in the long run as long as some services are produced for final demand. NGaI and Pissarides (2007), on the other hand, demonstrate that when capital is added to Baumol's model as an additional factor of production, the economy can reach a balanced growth path in the aggregate under certain circumstances while still exhibiting supply-side driven structural change due to differences in (exogenous) total factor productivity growth across sectors and a low elasticity of substitution across final goods. Against the backdrop of these theoretical contributions, structural change may influence GDP growth either way (or not at all).

\section{Testing Framework}

For a Cobb-Douglas economy with cost minimization and markup pricing, and an 'almost ideal' demand side in the sense of Deaton and Muellbauer (1980), Nordhaus shows that the first five syndromes described in the previous section can be interpreted econometrically as reduced-form equations which - under certain assumptions Nordhaus draws out - can be written as:

$$
\hat{x}_{i t}=\gamma_{0 i}+\gamma_{1} \hat{a}_{i t}+\gamma_{2} D_{t}+\varepsilon_{i t}^{p} \text {, }
$$

where $\hat{a}_{i t}$ is the growth rate (log difference) of productivity in industry $i$ at time period $t . \hat{x}_{i t}$ is a placeholder for different variables; it may stand for either real or nominal output growth, or price, wage or employment growth. $D_{t}$ is a panel of fixed time effects, $\gamma_{0 i}$ are fixed industry effects, $\varepsilon_{i t}^{p}$ is a random disturbance, and $\gamma_{1}$ and $\gamma_{2}$ are coefficients. Equation (14) can be estimated with pooled OLS. (EViews v.6 is used for the estimations.) 
Testing the sixth (and probably most worrisome) syndrome - the negative impact of structural change on overall economic growth - requires a different approach. Nordhaus proposes a non-parametric test. Overall productivity growth is a weighted average of the industries' productivity growth rates, with the industries' shares in last year's GDP as weights. ${ }^{2}$ If we track the shares over time, we can see whether the industries with low productivity growth gain weight or, alternatively, whether the GDP growth rate drops when more recent years are chosen as weighting (or base) years. If so, then the prediction of Baumol's model would be confirmed.

\section{Data}

With respect to data availability, I'm in a less comfortable position than Nordhaus. The main difference is that no capital stock or capital services data are available for Swiss industries. Therefore, I cannot follow Nordhaus in distinguishing between labour productivity growth and total factor productivity growth. This means that the analysis in this paper is restricted to labour productivity growth.

In the cross-section dimension, Nordhaus has data for 67 detailed industries and 14 broad industry groups. He claims that only 28 of the detailed industries (mainly from the industry group 'manufacturing') have relatively well-measured output. Nordhaus estimates each of his equations separately with data for the 67 detailed industries, the 28 well-measured industries, and the 14 industry groups.

The Swiss production account published by the Swiss Federal Statistical Office (OFS) distinguishes only 43 industries, one of which ('production of housing services by private households including homeowners' equivalent rent') is irrelevant for productivity analysis because, by assumption, production is carried out without labour input in this industry. 24 out of Nordhaus's 28 well-measured industries can also be identified in Swiss data. ${ }^{3}$ These industries are denoted with an asterisk in the appendix, which lists all industries and industry groups.

2 In the U.S., geometrical means of the industries' value added shares in two adjacent years are used as weights.

3 The distinction between 'measurable' and 'unmeasurable' sectors (the latter including construction, trade, finance, other services, and government) was introduced by GriLICHEs (1994). As Berndt and Hulten make clear in their introduction to a conference volume honoring Griliches (BERNDT and Hulten, 2007), the measurement problems in services sectors are not specific to the U.S., but "emanate from the fact that the units of measurement of the underlying product are very difficult to define" (p.5). 
The OFS has decided to publish industry productivity data only for what the Office calls the 'business sector', which means that no labour input data for the industry 'public administration' is publicly available. These data can be obtained, however, upon request from the Office. ${ }^{4}$ There are also differences between total output and employment on the one hand and their 'business sector' counterparts on the other hand in the industries 'health and social work', 'activities of membership organizations' and 'recreational, cultural and sporting activities' due to the involvement of 'non-profit institutions serving households' (NPISH) in the production process in these three industries. However, the differences in productivity growth between the for-profit and the non-profit segments of these three industries seem to be negligible. Therefore, I will look at the total economy and not just at the 'business sector' (which is what Nordhaus also does).

The OFS publishes two different datasets on labour input. For the economy as a whole, labour input is measured as total hours worked. Unlike in the U.S., however, no hours worked data are available for the industry level. Labour input is therefore measured with full-time equivalents here.

Regarding the time dimension, Nordhaus's dataset covers the period 1948 2001. He estimates equation (14) for the entire sample, 1948-2001, as a crosssection as well as with pooled cross-section and time series data. ${ }^{6}$ For the latter estimation, he constructs four sub-periods with business cycle watersheds (1959, 1973, 1989) chosen as break points.

Swiss data on industry output (nominal and real), and prices currently cover the period 1990-2007 for 14 major industry groups and 10 individual industries. They cover the period 1997-2007 for the remaining 32 industries. Fulltime equivalents are available for 1991-2007 for all industries. Wage data for all industries except 'agriculture, forestry, hunting and fishing' are available for 1993-2008.

I will estimate equation (14) for a cross-section of average growth rates over the period 1991-2007 (respectively 1997-2007). I will also construct four subperiods in a similar way as Nordhaus does. Turning points of the Swiss business cycle during the period I look at were the years 1997, 2000 and 2003, so the four

4 I would like to thank Mr. Gregory Rais from the OFS for providing these data to me.

5 For 'health and social work', data availability allows for a comparison. Productivity growth in both segments is basically identical, except (curiously) in 1993.

6 Note that this implies that for the cross-section estimation over the whole sample period with data for the broad industry groups, Nordhaus has only 14 observations. While many would agree that it is not sensible to do regression analysis with so few observations, I will replicate these estimations here also. 
sub-periods are 1991-1997, 1997-2000, 2000-2003, and 2003-2007. Unlike Nordhaus, I will also estimate equation (14) with annual data.

\section{Results}

\subsection{Results for the Cost and Price Disease}

Baumol's model predicts that industries with low relative productivity growth will exhibit high relative price increases. This hypothesis will be tested, applying the testing framework described in section 3 to Swiss data. Beforehand, it must be decided which prices to look at. In principle, one could either choose gross output deflators or value added deflators. Nordhaus argues in favour of using value added data because value added allows better than gross output for tracking the industrial source of technological advances that result in productivity growth. I will follow this lead.

Table 1 distinguishes between estimates for the full sample of 42 industries, the 14 major industry groups, and the 24 'well-measured' industries. The table shows that for the full sample of industries, the coefficient for productivity growth is significantly negative (at the $1 \%$ level) for the cross-section of average growth rates, the pooled estimation with four sub-periods, and the pooled estimation with annual data. For the 24 well-measured industries however, the coefficient is only significant for the cross-section and the pooled estimation with annual data. For the 14 major industries, all coefficients are negative, but insignificant.

Overall, these results yield evidence in favour of the cost and price disease. In the largest sample, industries with low relative productivity growth show significantly higher than average price growth. This finding is in line with Nordhaus's result for the U.S. Note, however, that my coefficients are much lower that those found by Nordhaus. On average, the absolute value of Nordhaus's coefficients is only slightly below one, which prompts him to state that "consumers capture virtually all the gains from technological change" (NordHAus, 2008, p. 10). This seems to be quite different in Switzerland, where the coefficient for productivity growth is around 0.2 on average in absolute terms. ${ }^{8}$ I will get back to this point below.

7 This is not unproblematic because of the impact of the business cycle on productivity. Even the multi-period average growth rates used in my pooled estimations may not be completely purged from business cycle effects because the sub-periods are rather short (sometimes only 4 years, as opposed to 13 years in Nordhaus's paper).

8 Following Nordhaus, I report two summary statistics at the bottom of the table. The 'weighted' statistic weights each coefficient with the number of observations. The 'unweighted' statistic weights each equation equally. 
Table 1: Impact of Productivity Growth on Price Growth (1991-2007)

\begin{tabular}{|c|c|c|c|}
\hline \multicolumn{4}{|c|}{ Dependent variable: dlog(p) } \\
\hline & \multicolumn{2}{|c|}{ Coefficient of dlog(prod) } & \# observations \\
\hline cross section & $-0.396^{* * *}$ & $(0.065)$ & 42 \\
\hline 4 sub-periods & $-0.159^{* * *}$ & $(0.059)$ & 136 \\
\hline annual data & $-0.221^{* * *}$ & $(0.032)$ & 480 \\
\hline \multicolumn{4}{|c|}{24 well-measured industries } \\
\hline cross section & $-0.482^{* * *}$ & $(0.095)$ & 24 \\
\hline 4 sub-periods & -0.088 & $(0.068)$ & 75 \\
\hline annual data & $-0.127^{* * *}$ & $(0.029)$ & 258 \\
\hline \multicolumn{4}{|c|}{14 industry groups } \\
\hline cross section & -0.210 & $(0.154)$ & 14 \\
\hline 4 sub-periods & -0.066 & $(0.063)$ & 56 \\
\hline annual data & -0.054 & $(0.032)$ & 224 \\
\hline \multicolumn{4}{|c|}{ Summary statistics } \\
\hline weighted & -0.163 & & \\
\hline unweighted & -0.200 & & \\
\hline
\end{tabular}

$\mathrm{p}$ = industry price level (deflator of gross value added),

prod = industry productivity level (gross value added per full-time equivalent)

Standard errors are in parenthesis. *, **, and ${ }^{* * *}$ denote significance at the $10 \%, 5 \%$, and $1 \%$ level, respectively. Estimates for constant terms not shown.

\subsection{Results for the 'Constant Real Share' Assumption}

Table 2 shows that Swiss data clearly reject the 'constant real share' assumption. Industries with high productivity growth grow faster on average than industries with low productivity growth. The coefficients are statistically significant in all nine estimations. If the progressive industries grow faster than the stagnant industries, then their 'real share' will rise; and this is a palliative against 'Baumol's diseases'.

My test results for the 'constant real share' assumption are very similar to those reported by Nordhaus. He also finds statistically significant positive coefficients when regressing U.S. real industry gross value added growth on productivity growth. (In fact, the 'constant real share' assumption is the only assumption or implication of Baumol's model that Nordhaus rejects.) Even in their magnitude (between 0.60 and 0.66 on average), my coefficients are similar to those 
estimated by Nordhaus. His unweighted average for the coefficients is 0.66 and his weighted average is 0.72 .

Table 2: Impact of Productivity Growth on Real Gross Value Added Growth (1991-2007)

Dependent variable: dlog(rgva)

Coefficient of $\mathrm{d} \log ($ prod $) \quad$ \# observations

\begin{tabular}{llrr}
\hline All 42 industries & & & \\
cross section & $0.529^{* * *}$ & $(0.142)$ & 42 \\
4 sub-periods & $0.515^{* * *}$ & $(0.063)$ & 136 \\
annual data & $0.690^{* * *}$ & $(0.028)$ & 480 \\
24 well-measured industries & & & \\
cross section & $0.824^{* * *}$ & $(0.207)$ & 24 \\
4 sub-periods & $0.467^{* * *}$ & $(0.090)$ & 75 \\
annual data & $0.636^{* * *}$ & $(0.040)$ & 258 \\
14 industry groups & & & 14 \\
cross section & $0.648^{* *}$ & $(0.159)$ & 56 \\
4 sub-periods & $0.725^{* * *}$ & $(0.072)$ & \\
annual data & $0.796^{* * *}$ & $(0.034)$ & \\
Summary statistics & & & \\
weighted & 0.665 & & \\
unweighted & 0.648 & & \\
\hline
\end{tabular}

rgva $=$ real industry gross value added,

prod $=$ industry productivity level (gross value added per full-time equivalent)

Standard errors are in parenthesis. ${ }^{*}, * *$, and ${ }^{* * *}$ denote significance at the $10 \%, 5 \%$, and $1 \%$ level, respectively. Estimates for constant terms not shown.

\subsection{Results for Nominal Growth}

The results given in Table 3 trivially reflect Tables 1 and 2 . The coefficients on nominal value added should be equal to the sum of the coefficients on price and output. Small deviations from that identity might occur, but if we look at the weighted average, for instance, we see that the identity almost exactly holds

9 In his paper, Nordhaus averages over all labour productivity (LP) and total factor productivity (TFP) specifications. I calculated averages for his LP specifications only for comparison with my estimates. 
Table 3: Impact of Productivity Growth on Nominal Gross Value Added Growth (1991-2007)

\begin{tabular}{llrr}
\hline $\begin{array}{l}\text { Dependent variable: dlog(ngva) } \\
\text { Coefficient of d log(prod) }\end{array}$ & \# observations \\
\hline All 42 industries & & & \\
cross section & 0.113 & $(0.142)$ & 42 \\
4 sub-periods & $0.361^{* * *}$ & $(0.074)$ & 136 \\
annual data & $0.469^{* * *}$ & $(0.038)$ & 480 \\
24 well-measured industries & & & \\
cross section & 0.308 & $(0.194)$ & 24 \\
4 sub-periods & $0.379^{* * *}$ & $(0.102)$ & 258 \\
annual data & $0.509^{* * *}$ & $(0.046)$ & 14 \\
14 industry groups & & & 56 \\
cross section & $0.445^{*}$ & $(0.237)$ & 224 \\
4 sub-periods & $0.667^{* * *}$ & $(0.087)$ & \\
annual data & $0.742^{* * *}$ & $(0.049)$ & \\
Summary statistics & & & \\
weighted & 0.501 & & \\
unweighted & 0.444 & & \\
\hline
\end{tabular}

ngva $=$ nominal industry gross value added,

prod $=$ industry productivity level (gross value added per full-time equivalent)

Standard errors are in parenthesis. *, ${ }^{* *}$, and ${ }^{* * *}$ denote significance at the $10 \%, 5 \%$, and $1 \%$ level, respectively. Estimates for constant terms not shown.

$(-0.163+0.665 \approx 0.501)$. The coefficients in Table 3 are all positive and - except for the cross-section estimates - significant at the $1 \%$ level, which means that industries with high relative productivity growth on average increase their share in nominal GDP. This is contrary to what Baumol's model predicts and also contrary to Nordhaus's finding for the U.S.

The reason for this difference between Switzerland and the U.S. obviously lies in the very different behaviour of prices. In both countries, industries with strong productivity growth advance faster in real terms, yet in the U.S., the reduction of relative prices in these industries outweighs the positive effect of productivity growth on real value added so that the overall effect of productivity growth on the progressive industries' nominal value added share is negative. In Switzerland, on the other hand, the progressive industries reduce their relative prices only slightly. Therefore, they are able not only to increase their 'real' output shares, but also their shares in nominal GDP. 


\subsection{Results for Employment Shares}

Baumol's model predicts declining employment shares of progressive industries. Table 4 shows that this prediction is strongly supported by Swiss data. Eight out of nine estimated coefficients are significantly negative, which means that industries with above-average productivity growth have below-average employment growth. Therefore, over time, the share of these industries in total employment falls. Nordhaus finds the same pattern for the U.S. His estimates for the coefficients are in the same range - between -0.28 and -0.34 on average - as those found for Switzerland. ${ }^{10}$

Table 4: Impact of Productivity Growth on Full-Time Equivalents Growth (1991-2007)

\begin{tabular}{llrr}
\hline Dependent variable: $d \log (f t e)$ & & & \\
& \multicolumn{2}{l}{ Coefficient of $\operatorname{dlog}(\mathrm{prod})$} & \# observations \\
\hline All 42 industries & & & \\
cross section & $-0.406^{* * *}$ & $(0.145)$ & 136 \\
4 sub-periods & $-0.515^{* * *}$ & $(0.066)$ & 480 \\
annual data & $-0.310^{* * *}$ & $(0.028)$ & 24 \\
24 well-measured industries & & & 75 \\
cross section & -0.142 & $(0.215)$ & 258 \\
4 sub-periods & $-0.568^{* * *}$ & $(0.093)$ & 14 \\
annual data & $-0.364^{* * *}$ & $(0.040)$ & 56 \\
14 industry groups & & & 224 \\
cross section & $-0.359^{* *}$ & $(0.158)$ & \\
4 sub-periods & $-0.277^{* * *}$ & $(0.073)$ & \\
annual data & $-0.204^{* * *}$ & $(0.034)$ & \\
Summary statistics & & & \\
weighted & -0.338 & & \\
unweighted & -0.349 & & \\
\hline
\end{tabular}

fte $=$ number of full-time equivalents,

prod $=$ industry productivity level (gross value added per full-time equivalent)

Standard errors are in parenthesis. *, **, and ${ }^{* * *}$ denote significance at the $10 \%, 5 \%$, and $1 \%$ level, respectively. Estimates for constant terms not shown.

10 Nordhaus notes that his results are robust to adding wage growth as a control variable. The same is true for my estimates. 


\subsection{Results for Wage Growth}

Baumol assumes uniform wage growth across industries; therefore, wage growth should not be correlated with productivity growth. Table 5 shows that the evidence on this assumption is mixed in Swiss data. Six coefficients are significantly positive at the $10 \%$ level or better, three are insignificant. One coefficient is even negative. These results are similar to those reported by Nordhaus for the U.S., who also finds small positive and negative coefficient values, depending on the sub-sample. His average unweighted and weighted coefficients are 0.038 and 0.042 , respectively, which are a bit higher than the Swiss values reported in Table 5. In any case, even if the coefficients may be regarded as statistically significant, they are too small to be economically significant. Even my highest estimate only suggests a 0.042 percentage point increase in wage growth per percentage point increase in productivity growth. Therefore, we can conclude that the evidence on Swiss wage growth is in line with the predictions of Baumol's model.

Table 5: Impact of Productivity Growth on Wage Growth (1993-2007)

\begin{tabular}{llrl}
\hline Dependent variable: $\operatorname{dlog}(w)$ & & & \\
& Coefficient of $\operatorname{dlog}($ prod $)$ & \# observations \\
\hline All 42 industries & & & \\
cross section & $0.035^{* *}$ & $(0.016)$ & 41 \\
4 sub-periods & $0.017^{* *}$ & $(0.008)$ & 132 \\
annual data & 0.001 & $(0.006)$ & 446 \\
24 well-measured industries & & & \\
cross section & $0.042^{*}$ & $(0.023)$ & 71 \\
4 sub-periods & $0.022^{* *}$ & $(0.010)$ & 238 \\
annual data & -0.001 & $(0.007)$ & 13 \\
14 industry groups & & & 52 \\
cross section & 0.008 & $(0.026)$ & 182 \\
4 sub-periods & $0.024^{* *}$ & $(0.007)$ & \\
annual data & $0.021^{* * *}$ & $(0.007)$ & \\
Summary statistics & & & \\
weighted & 0.010 & & \\
unweighted & 0.019 & & \\
\hline
\end{tabular}

$\mathrm{w}=$ nominal wage index,

prod $=$ industry productivity level (gross value added per full-time equivalent)

Standard errors are in parenthesis. ${ }^{*},{ }^{* *}$, and ${ }^{* * *}$ denote significance at the $10 \%, 5 \%$, and $1 \%$ level, respectively. Estimates for constant terms not shown. 


\subsection{Results for the Growth Disease}

Nordhaus suggests testing the growth disease hypothesis by weighting the growth rates of the industries' volume indices of value added with their value added shares in nominal GDP in alternative years. If the stagnant industries gain weight - as Baumol's model suggests - then the overall GDP growth rate should be higher if earlier years are used as weighting (or base) years. In other words, Baumol's model predicts that updating the base year leads to a drop in the overall GDP growth rate. Nordhaus finds exactly this pattern in U.S. data.

Table 6 shows, however, that in Swiss data we find the opposite pattern. Updating the base year generally raises the overall GDP growth rate, which means that the more productive industries gain weight over time. ${ }^{11}$ This result could have been anticipated from section 5.3, where the positive correlation between productivity growth and nominal value added growth has already been shown. Unlike the U.S., Switzerland is thus not affected by 'Baumol's growth disease'.

Table 6: Average Swiss Fixed-Weight Real GDP Growth with Different Base Years

\begin{tabular}{lc}
\hline Base year & Average GDP growth rate \\
\hline 2007 & $1.62 \%$ \\
2006 & $1.58 \%$ \\
2005 & $1.55 \%$ \\
2004 & $1.56 \%$ \\
2003 & $1.55 \%$ \\
2002 & $1.51 \%$ \\
2001 & $1.49 \%$ \\
2000 & $1.55 \%$ \\
1999 & $1.52 \%$ \\
\hline
\end{tabular}

\begin{tabular}{lc}
\hline Base year & Average GDP growth rate \\
\hline 1998 & $1.53 \%$ \\
1997 & $1.50 \%$ \\
1996 & $1.43 \%$ \\
1995 & $1.35 \%$ \\
1994 & $1.36 \%$ \\
1993 & $1.37 \%$ \\
1992 & $1.29 \%$ \\
1991 & $1.25 \%$ \\
1990 & $1.22 \%$ \\
\hline
\end{tabular}

11 To make perfectly clear what is done here: 2000, for instance, means that for each year 19912007 , the growth rates of real value added of the major industry groups are summed together to the overall GDP growth rate using the share of the respective industry group in nominal GDP in the year 2000 as weights. The 18 available weighting years (1990-2007) yield 18 alternative time series (quantity indices) for real GDP. The right column of Table 6 reports the average growth rates (geometrical means) for these 18 series over the period 1990-2007. 


\section{Discussion}

Overall, the evidence on whether Switzerland is affected by 'Baumol's diseases' is mixed. In line with the assumptions and predictions of Baumol's model of unbalanced growth, relative prices rise in stagnant sectors; and sectoral wage growth is largely independent of sectoral productivity growth. Also in line with the model, the employment share of the stagnant part of the economy rises. On the other hand, the 'constant real share' assumption is rejected. Progressive industries increase their 'share' in real GDP, and because this volume effect is stronger than the decline in their relative prices, progressive industries also increase their share in nominal GDP in Switzerland. This is the opposite of what Baumol's model predicts, and it is also the opposite of what NordHaus (2008) finds for the U.S. On average, expenditures do not shift toward the stagnant industries in Switzerland, thus there is no all-round 'cost disease' in this country. Also, Switzerland does not suffer from the 'growth disease', as the more productive industries gain weight over time instead of losing weight.

Why do the Swiss results differ from those for the U.S.? One possible explanation would be measurement differences. NordHaus (2008, p. 2), for instance, motivates his re-evaluation of Baumol's model by "improved approaches to measuring price and output indexes" in the U.S. So if the statistical offices in the U.S. have recently updated their measurement procedures, yet their Swiss counterpart (the OFS) has not, this might explain why the results are different. A comparison of measurement procedures between the U.S. and Switzerland reveals that despite internationally agreed-upon standards for setting up National Accounts, some differences remain (HARTWIG, 2006). The most substantial of these differences is the widespread application of quality-adjusted ('hedonic') price indices in the U.S. as opposed to Switzerland where almost no hedonic deflators are used. Hedonic deflators in most cases display less price growth than their traditional (non-quality-adjusted) counterparts; hence the deflated ('real') magnitudes grow faster when hedonic deflators are used. This explains part of the U.S. head start in 'real' economic growth over Europe since the mid-1990s (HaRTwig and Schips, 2005). However, if hedonic deflators were the reason behind the differences between Switzerland and the U.S. regarding relative price growth, then these differences should also show up in relative 'real' growth. As this is not the case, it is unlikely that measurement issues are responsible for the diverging results.

In search of an alternative explanation, it is perhaps useful to take a closer look at the increase in 'real shares' of the various Swiss industries. The industries with the steepest increase in their 'real share' (calculated as the share of deflated industry value added in total deflated gross value added, although this is problematic) 
are financial intermediation, communication, insurance, manufacturing, and 'health and social work'. Table 7 shows the 'real shares' of these industries in 1990 and 2007 as well as their nominal shares, average productivity growth rates, and average inflation rates. Among the five industries, there is only one - 'health and social work' - with low productivity growth. That progressive industries increase their 'real share' is in line with our results in section 5.2 and is also found by Nordhaus in U.S. data. What does not accord with the U.S. picture, however, is the pricing pattern. Prices in communication and insurance have dropped, but not nearly to the same extent as productivity has risen (see Table 7). Prices in manufacturing and financial intermediation have increased despite strong productivity growth (although for financial intermediation severe measurement problems exist). It will be remembered that Nordhaus suggests that the U.S. consumers capture almost all the gains from technological progress through lower prices. This is, as it seems, not the case in Switzerland. Since wages also do not respond much to productivity growth (see section 5.5), profit receivers are probably the main beneficiaries of technological progress. ${ }^{12}$

Table 7: Some Key Figures for Five Swiss Industries in Percent

\begin{tabular}{lccccc}
\hline & Manufacturing & $\begin{array}{c}\text { Commu- } \\
\text { nication }\end{array}$ & $\begin{array}{c}\text { Financial } \\
\text { intermediation }\end{array}$ & Insurance & $\begin{array}{c}\text { Health and } \\
\text { social work }\end{array}$ \\
\hline 'Real share' & $18.8(1990)$ & $1.4(1997)$ & $5.8(1990)$ & $1.7(1990)$ & $5.3(1990)$ \\
& $20.1(2007)$ & $3.2(2007)$ & $9.5(2007)$ & $3.1(2007)$ & $6.3(2007)$ \\
Productivity & +2.9 p.a. & +11.2 p.a. & +3.8 p.a. & +4.6 p.a. & +0.1 p.a. \\
& $(1991-2007)$ & $(1997-2007)$ & $(1991-2007)$ & $(1991-2007)$ & $(1991-2007)$ \\
Prices & +0.5 p.a. & -5.3 p.a. & +3.5 p.a. & -0.9 p.a. & +1.5 p.a. \\
& $(1990-2007)$ & $(1997-2007)$ & $(1991-2007)$ & $(1991-2007)$ & $(1991-2007)$ \\
Nominal & $21.2(1990)$ & $2.2(1990)$ & $3.8(1990)$ & $3.5(1990)$ & $4.9(1990)$ \\
share & $20.0(2007)$ & $2.7(2007)$ & $9.2(2007)$ & $4.5(2007)$ & $6.1(2007)$ \\
\hline
\end{tabular}

(years in parentheses)

The bottom line of Table 7 shows the development of the share of nominal industry value added in overall nominal gross value added for the five industries. Manufacturing and 'health and social work' are relatively 'well-behaved' industries from the point of view of Baumol's model. Manufacturing has high

12 Nevertheless, the share of wages in Swiss GDP rises over time according to OFS data. This is puzzling (see also HarTwig, 2008). 
productivity growth at low relative price growth so that despite an increase in its 'real share', the nominal share - which serves as weight for the summation of the industries' productivity growth rates to overall productivity growth - declines. If all progressive industries behaved like manufacturing, then Switzerland (like the U.S.) would show symptoms of the growth disease. 'Health and social work', on the other hand, is a relatively typical example of a stagnant industry. (I say 'relatively typical' because the 'real share' of this industry rises; and we've seen in section 5.2 that this is atypical for a stagnant industry.) Driven by both quantity and price expansion, the nominal share of 'health and social work' in gross value added rises, which, if not counteracted, would result in the cost and growth diseases. There are counterweights, however, namely the industries communication, insurance and - above all - financial intermediation. These three industries with strong productivity growth have managed to increase their nominal share - and thus their weight - which has thus far buttressed overall GDP growth. Whether this will still be the case in the future is, of course, an open question.

\section{Appendix: Industry Definition}

Industries correspond to the NACE codes (Version 4 Rev. 1 1993), in Switzerland known as NOGA (Nomenclature générale des activités).

\section{All 42 Detailed Industries}

(An asterisk denotes that the industry roughly corresponds to one of Nordhaus's 'well-measured industries')

Agriculture, forestry, hunting and fishing*

Mining and quarrying*

Manufacturing of food products; beverages and tobacco*

Manufacture of textiles*

Manufacture of wearing apparel; dressing and dying of fur*

Manufacture of leather and leather products*

Manufacture of wood and wood products*

Manufacture of pulp, paper and paper products*

Publishing, printing and reproduction of recorded media*

Manufacture of refined petroleum products, chemicals and chemical products*

Manufacture of rubber and plastic products*

Manufacture of other non-metallic mineral products*

Manufacture of basic metals* 
Manufacture of fabricated metal products*

Manufacture of machinery and equipment*

Manufacture of office machinery, computers, electrical machinery and apparatus n.e.c*

Manufacture of radio, television and communication equipment and apparatus*

Manufacture of medical, precision and optical instruments, watches and clocks

Manufacture of motor vehicles, trailers and semi-trailers*

Manufacture of other transport equipment*

Manufacture of furniture; manufacturing n.e.c.*

Recycling

Electricity, gas and water supply*

Construction

Sale, maintenance and repair of motor vehicles and motorcycles; retail sale of automotive fuel

Wholesale and retail trade*

Hotels and restaurants

Land transport; transport via pipelines; water transport; air transport*

Supporting and auxiliary transport activities; activities of travel agencies

Post and telecommunication*

Financial intermediation

Insurance

Real estate activities

Renting of machinery and equipment and of personal and household goods; other business activities

Computer and related activities

Research and development

Public administration and defence; compulsory social security

Education

Health and social work

Sewage and refuse disposal

Activities of membership organizations; recreational, cultural and sporting activities

Other service activities; private households with employed persons

\section{Industry Groups}

Agriculture, forestry, hunting and fishing

Mining and quarrying

Manufacturing 
Electricity, gas and water supply

Construction

Wholesale and retail trade; repair of motor vehicles and motorcycles and personal and household goods

Hotels and restaurants

Transport, storage and communication

Financial intermediation and insurance

Real estate, renting, business activities and $\mathrm{R} \& \mathrm{D}$

Public administration and defence; compulsory social security

Education

Health and social work

Other community, social and personal service activities

\section{References}

Baumol, William J. (1967), "Macroeconomics of Unbalanced Growth: the Anatomy of Urban Crisis", American Economic Review, 57 (3), pp.415-426.

Berndt, Ernst R. and Charles R. Hulten (ed.) (2007), Hard-to-Measure Goods and Services: Essays in Honor of Zvi Griliches, Chicago.

Deaton, Angus and John Muellbauer (1980), "An Almost Ideal Demand System", American Economic Review, 70 (3), pp.312-326.

Griliches, Zvi (1994), "Productivity, R\&D, and the Data Constraint", American Economic Review, 84 (1), pp. 1-23.

Gundlach, ERich (1994), "Demand Bias as an Explanation for Structural Change”, Kyklos, 47 (2), pp. 249-267.

Hartwig, Jochen (2006), „Messprobleme bei der Ermittlung des Wachstums der Arbeitsproduktivität - dargestellt anhand eines Vergleichs der Schweiz mit den USA“, Jahrbücher für Nationalökonomie und Statistik, 226 (4), pp.418-435.

Hartwig, Jochen (2008), "Trying to Assess the Quality of Macroeconomic Data - the Case of Swiss Labour Productivity Growth as an Example", Journal of Business Cycle Measurement and Analysis, 4 (1), pp. 37-61.

Hartwig, Jochen and Bernd Schips (2005), „Verzerrungen von Konsumentenpreisindices und ihr Einfluss auf das ,reale 'Wirtschaftswachstum - dargestellt am Beispiel der USA“, Jahrbücher für Nationalökonomie und Statistik, 225 (4), pp. 394-412.

Ngai, L. Rachel and Christopher A. Pissarides (2007), "Structural Change in a Multisector Model of Growth", American Economic Review, 97 (1), pp. 429-443. 
Nordhaus, William D. (2008), "Baumol's Diseases: a Macroeconomic Perspective", The B.E. Journal of Macroeconomics, 8(1) (Contributions), Article 9.

Oulton, Nicholas (2001), "Must the Growth Rate Decline? Baumol's Unbalanced Growth Revisited", Oxford Economic Papers, 53 (4), pp. 605-627.

Pugno, Maurizio (2006), "The Service Paradox and Endogenous Economic Growth", Structural Change and Economic Dynamics, 17 (1), pp.99-115.

Sasaki, Hiroaki (2007), "The Rise of Service Employment and Its Impact on Aggregate Productivity Growth", Structural Change and Economic Dynamics, 18 (4), pp. 438-459.

ten Raa, Thijs and Ronald Schettkat (2001), "Potential Explanations of the Real Share Maintenance of the Services", in: Thijs ten Raa and Ronald Schettkat (eds): The Growth of Service Industries. The Paradox of Exploding Costs and Persistent Demand, Cheltenham, pp. 29-41.

\section{SUMMARY}

Nordhaus (2008) has developed a testing strategy for what he calls 'Baumol's diseases', by which name he designates a number of by-products of structural change that are unwanted from an economic policy perspective. He finds that the U.S. economy is strongly affected by the 'diseases'. This paper applies Nordhaus's testing methodology to Swiss data. The results suggest that - unlike the U.S. Switzerland is not affected by the most serious of the 'diseases', namely the negative impact of structural change on economic growth. 